\title{
Addressing Capacities of Local Communities in a Changing Context in Nepal
}

Rolsted, Morten; Raju, Emmanuel

Published in:

Global Assessment Report on Disaster Risk Reduction 2019

Publication date:

2019

Document version

Publisher's PDF, also known as Version of record

Document license:

Unspecified

Citation for published version (APA):

Rolsted, M., \& Raju, E. (2019). Addressing Capacities of Local Communities in a Changing Context in Nepal. In Global Assessment Report on Disaster Risk Reduction 2019: Contributing Paper United Nations Publications. https://www.unisdr.org/we/inform/publications/66210 
Addressing Capacities of Local Communities in a Changing Context in

Nepal

Morten Rolsted,

Master of Disaster Management, Copenhagen Centre for Disaster Research, University of Copenhagen, Denmark

Emmanuel Raju,

Assistant Professor, Global Health Section, Department of Public Health, Copenhagen Centre for Disaster Research, University of Copenhagen, Denmark 


\begin{abstract}
Community-based approaches to disaster risk reduction has been the subject of attention for practitioners and scholars in the humanitarian and development sector for many decades. One of the core elements of the concept is the notion of inherent capacities of communities that get examined after every disaster. However, communities' capacities face an ever-increasing challenge of keeping pace with the changing world. Despite the relative influence of various factors being unknown, development, globalisation and the effects of climatic changes can inevitably affect these communities directly through prevalence and predictability of hazards or indirectly through, e.g. population growth, change of land use patterns and influence from outside. Therefore, it can be assumed that there can be an increased effect on people's lives and livelihoods. We approach this question of capacities for DRR in a changing world with findings from fieldwork in Lapsibot in Lamjung district in Western Nepal. In the paper, we critically examine the sufficiency of inherent capacities in local communities. While there is absolutely no question of strong capacities at the community level, this paper appeals for a more in-depth investigation of an extended notion of capacities, where the effects of the rapid changes and increasing impact of the outside world are taken into consideration. Further, it is argued that communities, in fact, need new and extended capacities, rather than only relying on inherent capacities, which is usually the main subject of capacity development in rural communities.
\end{abstract}




\section{Introduction}

Local actors in disaster risk reduction (DRR) and Community Based Disaster Risk Reduction (CBDRR) have gained increased attention (Hewitt, 2009; Luna, 2014; IFRCS, 2015; Davis and Alexander, 2016). This is based on the idea that the most sustainable solutions, come from promotion of local ownership to development based on peoples' own capacities and interest combined with external agents' expertise (Heijmans, 2004). Therefore, in general, communities we work with are thus not to be considered victims, but resourceful people who have the right to be involved (Wisner, Gaillard and Kelman, 2012). The aim of this paper is to explore external influences on capacities for disaster risk reduction using the case of Lapsibot in Lamjung district in Nepal.

One of the key factors of Priority 1 in the Sendai framework on 'Understanding Risk' necessitates a through vulnerability and capacity assessment and analysis. CBDRR is influenced by a number of internal and external factors as described in the Pressure and Release model (Wisner et al., 2003); in the circle of capacities and in the triangle of vulnerabilities (Wisner, Gaillard and Kelman, 2012); and depending on the approach taken by representatives/actors from the outside e.g. from governments, donors, INGO's and NGO's (Chambers, 1983; Bista, 1994; Luna, 2014).

In Nepal, which will be the subject of much of this paper, communities historically play a vital role in people's lives, physical and social security and people have thus found their own local resolutions to their issues and challenges (Neupane, 2001). Nepalese communities face disasters in the form of landslides, flooding, droughts and erratic rainfall and they are naturally aware of these disasters and have their own coping strategies, ranging from acceptance of the risk to actively trying to solve the problems by contacting government, media, humanitarian organisations and changing future direction (Sudmeier-Rieux et al., 2012).

How communities cope with disasters varies according to the available resources of the community. The impacts of neither climate change nor globalisation are expected to reduce in magnitude in the future (Taran and Geronimi, 2013; IPCC, 2014). If a community, e.g. relies on seasonal rains for rain-fed agriculture, what capacity does the same community then possess to deal with delayed arrival of the monsoon with erratic rainfalls, which damages the agricultural systems, and which increases the risk of landslides? In the Hindu Kush Himalaya Assessment, Wang et al. (2019, p. 18), argue, that “[...] the drivers of change to environmental, sociocultural, and economic sustainability in the $\mathrm{HKH}$ are interactive, inextricably linked, and increasingly influenced by regional and global developments". When met with these externally given and closely linked factors that have a marked effect on the lives and livelihood of rural people it is relevant to question whether the capacities 
and the coping strategies are sufficient to effectively deal with the increased and changed risks or only sufficient to deal with the risks for which they have developed their strategies.

\section{Theoretical foundations}

\section{Communities}

The concept of communities is fundamental in the approach of CBDRR and CBDRM. The concept originally meant a small group of people that shared ways of life, beliefs and who trusted and interacted with each other (Delica-Willison and Gaillard, 2012). McMillan and Charvis (1986, p. 9), argue that community can be described by " a feeling that members have of belonging, a feeling that members matter to one another and to the group, and a shared faith that members' needs will be met through their commitment to be together". The Nepalese anthropologist Dor Bahadur Bista (1994, pp. 143, 144) argues that there is a certain "localised" notion of community in the Nepalese villages. People relate to their local conditions and mutual responsibilities and consider the outside world "abstract". In his study of social capital mobilisation after the 1934 Kathmandu Valley earthquake, Bhandari (2014) mentions another evidence of the strong sense of community in Nepal, namely the practice of Guthi amongst Newar communities. This is a traditional way of mobilising local/community volunteers and other resources for cultural and religious purposes and maintenance of infrastructure. To this day, individuals continue to take strength in their belongingness to community through social ties.

Capacities

The above description of communities implies the communities have inherent capacities. Wisner et al. argue, that local communities have "resources, networks, knowledge and skills" (Wisner, Kelman and Gaillard, 2014, p. 15), to avoid that a hazard turns into a disaster. These capacities can be divided into resources that are either physical, natural, political, economic, social or human. Of interest in a Nepalese context, it is worthwhile mentioning the findings of Bhandari (2014) and Bhandari, Okada and Knottnerus (2011) in studies of social capital mobilisation, and of urban rituals and disaster risk coping, in connection with the 1934 Kathmandu Valley earthquake. It is argued that there are strong capacities in social capital, in local organisations such as youth groups, mothers' groups and scouts and in the ritual activities that are embedded in a community, but that these capacities are not sufficiently recognised.

According to Wisner et al., people can control their own capacities. However, they cannot control external conditions, which either create opportunities or hazards and vulnerability (Wisner, Kelman and Gaillard, 
2014). Therefore, it gives meaning to address the capacities in connection with CBDRR (Ibid.). Acceptance of this idea is core to much of the academic work done on CBDRR. Consequently, a core issue is how to build and further strengthen those capacities. This is not merely a question of promotion of local knowledge but rather that the insights of communities and those from the outside support each other. The external actors' ability to interact in planning and dialogue is decisive for the success of participatory risk assessments (Heijmans, 2004).

Even though local resources are available, people might not be able to access these resources due to a number of issues, including those that the community cannot control (Wisner, Gaillard and Kelman, 2012). This is also brought forward by Cardona (2004) amongst others, who mentions three foundations for vulnerability: physical and socio-economic fragility and lack of resilience. In connection with landslides Hadmoko and Mauro (2012) state that those staying in areas prone to landslides are those who cannot resettle in safer places. Therefore, even if people mostly know of the hazards, they lack the power for changing the circumstances. This corresponds to the note that vulnerability in a particular context has causes rooted in outside conditions. Those are conditions that the local community has limited influence on (Wisner, Kelman and Gaillard, 2014). These conditions can be either social, economic or political structures in society, that influence each other and also have an effect on making marginalised communities more vulnerable (Ibid.).

Ultimately, this raises the issue of whether the "inherent" capacities that are core in CBDRR are sufficient to strengthen the communities in their ability to influence external conditions. This issue becomes even more relevant when the external conditions change rapidly, e.g. via climate change, globalisation and population growth. While conducting capacity assessments, it is not only important to map out capacities within the community but to analyse how these identified capacities are influenced by external factors (Hagelsteen and Burke, 2016).

\section{Methodology}

The field study aimed at exploring how capcities are influenced by external factors in the context of CBDRR with the main data coming from a small village called Lapsibot in Lamjung district in Nepal. The article is based on fieldwork conducted in April 2018. Landslides are considered one of the most prevalent hazards in Nepal due to the geological, topographical and climatological conditions of the country combined with human activity having strong impacts on people's lives and livelihoods and the overall economy of the country (MoHA, 2015). 
Lapsibot in Lamjung district was chosen after consultation with Nepal Red Cross Society (NRCS), given its long history of landslides, and as it was assessed that it would be relatively accessible in terms of available information. Approximately 280 - 300 people live in Lapsibot, and there are approximately 75 households. The vast majority of the inhabitants come from the Gurung ethnic group, and a minority are from the Bishokarma group (low-caste). The major sources of income come from remittances from migrant workers and agriculture. Nepal Red Cross had been actively involved in disaster risk reduction in the village from $2012-2017$. Before this, the village had not been subject to much attention from outside actors.

Stakeholders involved were Lapsibot community members, NRCS staff members and district committee members. The research was based on stakeholder consultation with the application of key informant interviews (one village leader and one NRCS staff member), group interviews (two interviews with three NRCS staff members and three village leaders respectively), focus group discussion (eight NRCS district committee members), historical timeline and community mapping (15 - 20 community members). The different tools of data collection were inspired by the IFRCS Vulnerability and Capacity Assessment approach (IFRCS, 2003) focused on various aspects of vulnerabilities and capacities with regard to disaster risk reduction in Lapsibot.

Historical timelines were drawn with the community members to understand what impacts different disasters have had in the past and how that has been changing over time. Further, community mapping aided in identifying different risks and vulnerabilities in Lapsibot. Additionally, transect walks, observations and informal conversations were used to gather information. The meetings with the community members were arranged during gaps and after their daily work, in order not to bring too much disturbance in their busy daily schedules. Different sources of information were used as a mode of triangulation. Interviews were recorded and transcribed with the help of Nepalese interpreters. The data was coded using a grounded theory approach (Corbin and Strauss, 1990).

\section{Findings and Discussion}

Lamjung is reported to be highly prone to landslides, which was confirmed through the interaction with people in Lapsibot. It became evident that the area was prone to different hazards, but the hazard of landslides was clearly the most pronounced. There was a long history of landslides that for years had impacted their lives and livelihoods. The impact of landslides was not so much in terms of casualties but more on their subsistence and 
livelihoods via killing livestock and destroying agricultural land and infrastructure. In this section, findings from Lapsibot are presented and discussed in relation to the theoretical foundations presented above.

\section{Migration}

In Lapsibot, community members and NCRS representatives reported of strong migration out of the area. Especially young people migrated, which had a strong impact on the village. People were reported to migrate because of lack of opportunities locally. Interestingly, this was mentioned as a general problem for many villages in Lamjung. Migration was found to have an immediate effect on the livelihoods of those who remained, either because they did not have the opportunity to move or did not want to move. It was reported that mainly the old and children were still there. It further was reported to have long-term effects via lost possibilities for development and change locally. It was mentioned, however, that there were examples of people returning at a later stage, benefitting the communities.

Migration is a sign that external issues influence both vulnerabilities and capacities. Respondents indicated that the reason for migration was the need for employment, often meaning going abroad. Political structures do not create possibilities for income. This has an adverse effect on social and economic conditions in Lapsibot. The migrants are often seen as agents of change and whose work could benefit the society. But in this rather bleak picture, it should also be remembered that some people who had gone abroad have come back and used their acquired skills and finances to create jobs and opportunities for others.

In other studies, Aryal also reports that there had been changes in migration patterns. Previously people mostly joined the British or Indian army and returned after finishing their service. When they returned, they brought financial resources and knowledge with them benefitting the local community. Now, people did not return after migrating with the loss of opportunities for the local community as a consequence (Aryal, 2014).

Does the global scenario play a role in capacities for DRR? Studies indicated the effects of globalisation through migration. It did appear that there was a "push" towards migration due to lack of opportunities and a "pull" because of the opportunities that had become "available" in other places. On the positive side, remittances do provide income to the rural communities, and there are examples of people bringing skills and resources with them back to the communities. On the negative side, there are resources lost on the short-term, due to lack of workforce locally and in the long-term, because people do not move back. Both the present study in 
Lamjung and previous research indicated that this depletes the local capacities in terms of loss of opportunities and change.

One issue which is of interest to this article is the connection between migration and globalisation which shows through the demand for "transnational" labour, which is argued not to have resulted in the strengthening of labour, as corporations have "[...] placed production facilities and activities in regions where labor was abundant and politically docile". (Bonanno, 2014, p. 37). The connection between globalisation and migration is also mentioned as a substantial loss through brain-drain in some developing countries, which has an adverse effect on the growth and productivity (Taran and Geronimi, 2013). However, they also mention that, e.g. remittances and new skills brought back home are positive side effects of migration (Ibid.). One could argue that migration is also a consequence of the lack of opportunities locally, wherefore you will seek new opportunities. You can, therefore, argue that there is a "pull" and "push" for labour migration. The effects of globalisation on rural communities have been debated for decades. The results of globalisation have in many respects been impressive with accelerating trade, growing participation of developing countries and falling trade tariffs (Killick, 2001). Both Killick and Bonanno do conclude that there are both potentially positive impacts through, e.g. growth and negative impacts of globalisation on rural communities through the danger of being left behind (Killick, 2001; Bonanno, 2014).

\section{Governance}

In the case study in Lamjung, the risk of landslides in the area increased through conflicts and hazards related to the management of natural resources. It was quite clear that this was beyond the control of the community. These conflicts originated in disputes on land-use, e.g. the need for areas for grazing vs the need for forest-covered areas with their products and protective features against, e.g. landslides.

Conflicts concerning natural resources, depletion of resources, impacts of climate change, inadequate support from authorities and migration all increased the vulnerability of the communities. Those who were most severely impacted were the most vulnerable and poor segments. Even if people had knowledge of hazards, they prioritised other issues for their subsistence higher and therefore stayed in landslide-prone areas. The indicated reason for this was the lack of other options. One of the key factors with direct links to climate change is that of health. Health services was a major matter of concern in Lapsibot. People from Lapsibot walk a substantial 
distance for the nearest health post. The community members had asked for support from the local government representatives but claimed that they had not been able to get any help.

These all have a direct impact on the people who are directly dependent on agriculture and natural resources for their subsistence. For those people and especially for the poorest and most vulnerable, failure of crops and environmental degradation have strong impacts (Uitto and Shaw, 2016). Climate change is likely to affect the Hindu Kush Himalaya region strongly. Changing monsoon patterns with more and stronger storms can negatively impact agriculture, peoples' livelihoods and destroy infrastructure and can result in an increased risk of hazards (Wang et al., 2019).

When raising the issue of the communities not being able to influence governance, climate change and globalisation, the natural question in our judgement is to ask whether they can be equipped with the capacities to do so. Increased capacities are core to both disaster risk reduction and sustainable development. The present study in Lapsibot, for instance, indicates local social capital including networks, organisations, beliefs and culture as described by Bhandari et al. (2011) is an important aspect (yet frequently ignored). The need for a more adaptive, reflective and inclusive approach to local governance has been mentioned as necessary to address sustainable development and DRR simultaneously (Gentle and Maraseni, 2012; Sudmeier-Rieux et al., 2012). Implicitly this denotes addressing capacities not only from the isolated viewpoint of the rural community but in a broader perspective; how to enhance the capacities of all actors to engage in interactions that encompass sustainable development and DRR simultaneously. Bearing the case studies above in mind, it is not realistic to assume that they automatically have the strength to involve themselves. However, the case of Lapsibot in Lamjung, and the studies by Gentle and Maraseni (2012) and Südmeier-Rieux et al. (2012) confirm that rural communities have capacities that should be built upon and that there is potential scope for addressing the capacities of communities together with the capacities of other stakeholders. This should still be done in a way that the communities are involved for instance through integrated rural development as one case study suggested. Even though this study only concerns communities in hill districts in Nepal, we do believe that many of the findings can be generalised outside the country as well. Rural communities that are faced with the impacts of climate change and globalisation also in other parts of the world can be expected to meet similar if not the same challenges of dealing with these issues. Post disaster recovery studies have shown that external actors may undermine existing capacities and factors such as privatisation have an effect on communities' rights and access to resources (Raju, 2013). 
Another issue related to governance is mentioned by Gentle and Maraseni (2012), who observed that the production of non-timber forest products was threatened by over-exploitation of natural resources. Overall, Gentle and Maraseni claim that the issues reported appear beyond the capacity of the communities. The authors suggest what can be considered a more reflective and inclusive approach to support to the communities via technical support and research and considering climate change adaptation as part of overall development and integrated at various levels - locally in the district and nationally. In line with this Südmeier-Rieux et al. (2012, p. 689) conclude that there is "[....] need for integrated rural development and landslide risk reduction programs that are based on an understanding of local priorities and beliefs, which may vary considerably depending on social and economic status."

In studies on coping strategies and landslides in two villages in Dolakha district in Central-Eastern Nepal, Südmeier-Rieux et al. (2012) found that like in the case of Lamjung, landslides was a major hazard, having a strong impact on people's livelihoods, and which was expected to increase in occurrence in the future due to more intense rainfalls and road construction. Gentle and Maraseni, (2012) conducted a research study of remote communities in Jumla district in western Nepal, to examine the adaptation practices to climate change by rural mountain communities and the relationship to poverty and livelihoods. The researchers found evidence that climate change had a negative impact on people's livelihoods in the village. Changed weather patterns with erratic rainfall and drought increased the uncertainty of the agriculture which provided subsistence and the collection of non-timber forest products.

This call for another perspective of governance is perhaps most clearly spelled out by Aryal (2014, p. 145) who concludes that "[...] it is interesting to note that participatory local risk analysis is still organised from the perspective of disaster risk as such and not very often as part of an overall diagnosis of local development needs and the factors that promote disaster resilience locally. That is to say, often it is disaster risk that is at the centre of concern and not development in a more general sense. The significance of this for local disaster vulnerability and (sustainable)development may be very important in Nepal.". It is evident that with increased neo-liberal ways of functioning of the state, DRR governance will not be successful without active engagement of different political actors (Jones et al., 2014). Therefore, it is clear that it must not be forgotten that governance is not only about government but needs to adopt an all-encompassing approach to different actors in DRR. Making DRR everyone's business as disasters cut across all party lines is a crucial step towards being more inclusive (Raju and da Costa, 2018). 


\section{Capacities}

One of the respondents in the study of Lapsibot stated- "People of the community do not look for options in terms of programs, they have been participating as they are provided. They think why they should say no as they have been provided with the opportunity of at least those programs which will also help the community". This also stems from the fact that these communities have not been exposed to many external actors along with a low awareness on aspects of disaster risk management.

As mentioned, Lapsibot in Lamjung had been supported by NRCS for approximately five years. The support acts to be an example of a successful CBDRR project with a positive impact, based on a process that included the knowledge of both outsiders and locals. It had enabled the locals to plan for risk-reduction measures, and the activities were owned and implemented by the community. The interventions were observed to have had a positive impact on the capacities and vulnerabilities of the village. The inherent capacities had been strengthened. Those were primarily centred around political resources in terms of community leadership and social resources via the networks that existed in the village, and as such, the project did consider the social capital of the village. Other capacities such as human resources, physical resources and economic capacity had also been built via the project.

Despite the frequent occurrence of natural hazards, people continued living in the village and did not consider other options such as moving to other places as possible. Overall a picture emerges of local communities with inherent capacities regarding knowledge and coping strategies, but that they are met with issues that eventually are beyond their control. The case highlights that rural communities do have inherent capacities and that external conditions influence the capacity as well as vulnerability and risk of the rural communities, as also highlighted in the theoretical section. However, what does not come out in most studies clearly is that challenges such as climate change and globalisation are beyond the inherent capacity of the communities, calling for a broadened perspective to address the challenges. This muddy mixture of capacities as a universal concept blurs the need to address external factors influencing vulnerability.

The overall impression was in line with the studies by Gentle and Maraseni and Südmeier-Rieux et al.; the communities have inherent capacities and have found strategies to cope and adapt to the living conditions in their area.

The findings from Lapsibot indicate that while there may be positive changes with regard to capacity development projects, inherent capacities within communities are not sufficient to address fundamental 
causes of vulnerability that are predominantly driven by external factors. According to the different studies, the communities do not have the power or influence to raise these issues towards the external actors. This power issue is more evident depending on the socio-economic status of the group in question. According to the findings by Gentle and Maraseni (2012), social structures, inequities and power relationships are promoted this way; the strategies the poor chose pushes them to further vulnerability and risks. It can be argued that these are governance issues and that a key question could be how to enable the communities to raise concerns like these towards the authorities.

Aryal (2014) presents nine case studies from the Terai (the southern plains of the country) and the hilly regions. The case studies indicate different perspectives of vulnerability. In one case depletion of local knowledge and of labour for agriculture (due to migration) meant that the number of crops per year was reduced from four to three. According to the study, regular use of the land had a stabilising effect on the soil. Therefore, the reduction in crops had adverse effects on soil stability and in turn, increased the risk of landslides.

In the study by Südmeier-Rieux et al. (2012), it was also found that people had high knowledge of where and why landslides happen and did have coping strategies. However, they remained in the same areas. Further, landslide risks were prioritised lower than immediate needs such as health and food. The researchers found this to be more pronounced for the poorest of the communities in comparison to more well-off groups. According to the researchers, differences in resources, beliefs that in turn have their origin in issues such as ethnicity, social status and education resulted in marked differences in terms of coping strategies.

According to Gentle and Maraseni (2012), the communities in their study seemed to be challenged in their capacity to adapt to the changed environment, and the researchers mention limited livelihood options, limited knowledge and poor assets and inadequate external support as reasons. Crop diversification and selection of drought-resistant crops were reported to be the responses commonly used.

As mentioned, people lacking economic resources appeared worst stuck, and the researchers conclude that they were coping - not adapting and that their coping strategies included labour migration, child labour and consumption loans. These strategies, in turn, seemed to make people sink deeper into poverty and vulnerability. Social structures, inequities and power relationships are promoted this way; the strategies the poor chose pushes them to further vulnerability and risks. (Gentle and Maraseni, 2012). 


\section{Conclusion}

By now, there is substantial evidence on ill-planned development projects leading to increased disaster risk (Munene, Swartling and Thomalla, 2018). Part of this development can arguably be traced back to globalisation and part of the consequences can be seen in aspects of climate change. The question is whether this also is an opportunity for pursuing new/extended capacities that strengthen rural communities' abilities towards the rapidly changing external world.

The case of Lapsibot and the other studies from Nepal show rural communities often have capacities and mechanisms to deal with situations that they have adapted to including temporary and slow changes. However, it is not reasonable to assume that they easily can adapt to rapid and fundamentally changed conditions caused by climate change or globalisation. Neither is it realistic to assume that solutions can be based entirely on their existing capacities.

It can be argued that when listing factors like those above, we go beyond the traditional scope and definition of local capacities in CBDRR and instead touch upon factors that are root causes and dynamic pressures that result in vulnerability as for instance described in the pressure and release model (Wisner et al., 2003). We do not argue that these are not externally given and rooted in, e.g. economic and societal conditions beyond the control of the community, but that this is an area with an option for a new set of capacities.

The findings from Lapsibot indicate that external conditions influence the capacity as well as vulnerability and risk of the rural communities. These challenges are beyond the inherent capacity of the communities and include issues such as climate change and globalisation in the form of migration. It, therefore, is clear about a need to address these issues not only from a local/community level but through an integrated approach addressing multiple issues and involving multiple stakeholders, also outside the local communities. This does in turn call for a changed perspective on capacities, encompassing all actors. Still, the focus should be on local communities, strengthening their capacities and building new, enabling them to influence the external factors that influence their existence.

It is quite clear that there is a major gap in understanding the full spectrum of capacities for DRR. The paper drives the point that capacities in the context of disaster risk reduction have always been seen as what exists within a community. It is true that external actors responding to disasters often only see the vulnerability side and ignore capacities to a large extent. However, these capacities within a community may not be the only way of addressing vulnerabilities arising from root causes in society that may predominantly be external to communities. 
The case of Lapsibot reveals thought-provoking insights to further investigate the critical links between capacities and the various aspects that influence vulnerabilities from varied external sources. Therefore, the notion of capacities for DRR needs to be strengthened by taking a nuanced outlook on how capacities are organised and what can these capacities influence for change. The ongoing work on different policies for DRR at the national level or implementation of the Sendai framework must take into account different facets of capacities and their external influences. 


\section{Bibliography}

Aryal, K. R. 2014. Disaster vulnerability in Nepal. In: International Journal of Disaster Risk Reduction. Elsevier. Vol. 9: $137-146$.

Bhandari, R. B. 2014. Social capital in disaster risk management; a case study of social capital mobilization following the 1934 Kathmandu valley earthquake in Nepal. In: Disaster Prevention and Management. Vol. 23, Issue 4: 314-328.

Bhandari, R. B., Okada, N. and Knottnerus, J. D. 2011. Urban ritual events and coping with disaster risk a case study of Lalitpur, Nepal. In: Journal of Applied Social Science. Vol. 5, Issue 2: 13-32.

Bista, D. B. 1994. Foreign Aid and Development. Chapter 7. In: Fatalism and Development: Nepal's Struggle for Modernization. Orient Longman Limited. Hyderabad.

Bonanno, A. 2014. Globalization. Chapter 2. In: Handbook of Rural Development. Edward Elgar Publishing, Incorporated. Oxford.

Cardona, O. D. 2004. The Need for Rethinking the Concepts of Vulnerability and Risk from a Holistic Perspective: A Necessary Review and Criticism for Effective Risk Management. Chapter 3. In: Mapping Vulnerability Disasters, Development \& People. Earthscan. Oxford.

Chambers, R. 1983. Rural Poverty Unperceived. Chapter 1. In: Rural Development - Putting the Last First. Prentice Hall. Edingburgh.

Corbin, J. M. and Strauss, A. 1990. Grounded Theory Research: Procedures, Canons, and Evaluative Criteria. In: Qualitative Sociology. Vol. 13, Issue 1: 3-21.

Davis, I. and Alexander, D. 2016. Recovery from Disaster, Routledge Studies in Hazards, Disaster Risk and Climate Change. Oxford. UK. Routledge.

Delica-Willison, Z. and Gaillard, J. C. 2012. Community Action and Disaster. Chapter 59. In: The Routledge Handbook of Hazards and Disaster Risk Reduction. Routledge. Oxford

Gentle, P. and Maraseni, T. N. 2012. Climate change, poverty and livelihoods: Adaptation practices by rural mountain communities in Nepal. In: Environmental Science and Policy. Elsevier Ltd. Vol. 21: 24-34.

Hadmoko, D. S. and Mauro, E.-D. 2012. Landslide and other Mass Movements. Chapter 25. In: The Routledge Handbook of Hazards and Disaster Risk Reduction. Routledge. Oxford.

Hagelsteen, M. and Burke, J. 2016. Practical aspects of capacity development in the context of disaster risk reduction. In: International Journal of Disaster Risk Reduction. Vol. 16: 43-52. 
Heijmans, A. 2004. 'From Vulnerability to Empowerment. Chapter 8. In: Mapping Vulnerability - Disasters, Development \& People. Earthscan. Oxford.

Hewitt, K. 2009. Culture and risk: Understanding the sociocultural settings that influence risk from natural hazards. International Centre for Integrated Mountain Development (ICIMOD).

IFRCS. (International Federation of Red Cross and Red Crescent) 2003. VCA Guideline. International Federation of Red Cross and Red Crescent

IFRCS. (International Federation of Red Cross and Red Crescent). 2015. World Disaster Report 2015: Focus on local actors, the key to humanitarian effectiveness. International Federation of Red Cross and Red Crescent IPCC (Intergovernmental Panel on Climate Change). 2014. Summary for Policymakers, Climate Change 2014: Synthesis Report. Contribution of Working Groups I, II and III to the Fifth Assessment Report of the Intergovernmental Panel on Climate Change. Intergovernmental Panel on Climate Change.

Jones, S. et al. 2014. Governance struggles and policy processes in disaster risk reduction: A case study from Nepal. In: Geoforum. Elsevier Ltd. Vol. 57: 78-90.

Killick, T. 2001. Globalisation and the rural poor. In: Development Policy Review. Vol. 19, Issue 2: 155-180.

Luna, E. M. 2014. Community-based Disaster Risk Reduction and Disaster Management. Chapter 4. In: Disaster Management: International Lessons in Risk Reduction, Response and Recovery. Routledge. Oxford McMillan, D. W. and Chavis, D. M. 1986. Sense of community: A definition and theory. Special Issue: Psychological sense of community, I: Theory and concepts. Journal of Community Psychology. Vol. 14, Issue: 1: 6-23

MoHA (The Government of Nepal - Ministry of Home Affairs and Disaster Preparedness Network-Nepal). 2015. Nepal disaster report 2015. The Government of Nepal.

Munene, M. B., Swartling, Å. G. and Thomalla, F. 2018. Adaptive governance as a catalyst for transforming the relationship between development and disaster risk through the Sendai Framework? In: International Journal of Disaster Risk Reduction. Elsevier Ltd. Vol. 28, Issue September 2017: 653-663.

Neupane, B. D. 2001. Volunteerism in Nepal. A Perspective on the Existing Policies and Practices. Chapter 1. In: Volunteerism in Nepal. National Planning Commission (NPC) / National Development Volunteers Service (NDVS) and UN Volunteers Nepal. Kathmandu

Raju, E. 2013. Housing Reconstruction in Disaster Recovery: A Study of Fishing Communities Post- tsunami in Chennai, India. In: PLOS Currents Disasters. Vol 5. 
Raju, E. and da Costa, K. 2018. Governance in the Sendai: a way ahead? Disaster Prevention and Management: An International Journal. Vol. 27, Issue 3: 278-291.

Sudmeier-Rieux, K. et al. 2012. A case study of coping strategies and landslides in two villages of Central-Eastern Nepal. In: Applied Geography. Elsevier Ltd. Vol.: 32, Issue 2: 680-690.

Taran, P. A. and Geronimi, E. 2013. Globalization, Labour and Migration: Protection is Paramount. 3. International Labour Organisation. Geneva

Uitto, J. I. and Shaw, R. 2016. Introduction. Chapter 1. In: Sustainable Development and Disaster Risk Reduction. Springer. Tokyo

Wang, Y. et al. 2019. Drivers of Change to Mountain Sustainability in the Hindu Kush Himalaya. Chapter 2. In: The Hindu Kush Himalaya Assessment. International Centre for Integrated Mountain Development (ICIMOD).

Wisner, B. et al. 2003. The Disaster Pressure and Release Model. Chapter 2. In: At Risk-Natural hazards, people's vulnerability and disasters. Routledge. Oxford

Wisner, B., Gaillard, J. C. and Kelman, I. 2012. Framing disaster: theories and stories seeking to understand hazards, vulnerability and risk. Chapter 3. In: The Routledge Handbook of Hazards and Disaster Risk Reduction. Routledge. Oxford.

Wisner, B., Kelman, I. and Gaillard, J. C. 2014. Hazard, vulnerability, capacity, risk and participation. Chapter 2. In: Disaster Management: International Lessons in Risk Reduction, Response and Recovery. Routledge. Oxford. 